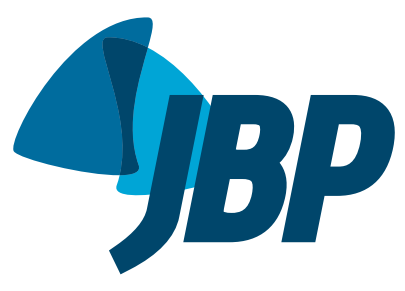

\title{
Lung function and left ventricular hypertrophy in morbidly obese candidates for bariatric surgery
}

\author{
Paulo de Tarso Müller ${ }^{1,2}$, Hamilton Domingos ${ }^{3}$, Luiz Armando Pereira Patusco ${ }^{1,2}$, \\ Gabriel Victor Guimarães Rapello ${ }^{1}$
}

1. Laboratório de Fisiopatologia Respiratória - LAFIR - Universidade Federal de Mato Grosso do Sul, Campo Grande, Brasil.

2. Disciplina de Pneumologia, Faculdade de Medicina, Universidade Federal de Mato Grosso do Sul, Campo Grande, Brasil.

3. Disciplina de Cardiologia, Faculdade de Medicina, Universidade Federal de Mato Grosso do Sul, Campo Grande, Brasil.

Submitted: 23 February 2015

Accepted: 5 July 2015.

Study carried out in the Laboratório de Fisiopatologia Respiratória - LAFIR Universidade Federal de Mato Grosso do Sul, Campo Grande (MS) Brasil.

\begin{abstract}
Objective: To look for correlations between lung function and cardiac dimension variables in morbidly obese patients, in order to test the hypothesis that the relative size of the small airways is independently correlated with left ventricular hypertrophy. Methods: This was a retrospective study involving 192 medical records containing a clinical protocol employed in candidates for bariatric surgery between January of 2006 and December of 2010. Results: Of the 192 patients evaluated, 39 (10 males and 29 females) met the inclusion criteria. The mean BMI of the patients was $49.2 \pm 7.6 \mathrm{~kg} /$ $\mathrm{m}^{2}$, and the mean age was $35.5 \pm 7.7$ years. The $\mathrm{FEF}_{25-75} / \mathrm{FVC}, \%$ correlated significantly with left ventricular posterior wall thickness and relative left ventricular posterior wall thickness, those correlations remaining statistically significant $(r=-0.355$ and $r=$ -0.349 , respectively) after adjustment for weight, gender, and history of systemic arterial hypertension. Stepwise multivariate linear regression analysis showed that FVC and $\mathrm{FEV}_{1}$ were the major determinants of left ventricular mass (in grams or indexed to body surface area). Conclusions: A reduction in the relative size of the small airways appears to be independently correlated with obesity-related cardiac hypertrophy, regardless of factors affecting respiratory mechanics (BMI and weight), gender, or history of systemic arterial hypertension. However, FEV 1 and FVC might be important predictors of left ventricular mass in morbidly obese individuals.
\end{abstract}

Keywords: Obesity; Spirometry; Echocardiography; Body mass index

\section{INTRODUCTION}

Obesity is an isolated risk factor for cardiovascular disease; it can lead to cardiac hypertrophy followed by dilated cardiomyopathy, predisposing to fatal arrhythmias.(1) Obesity also causes organ-specific changes, which are due to a direct mechanical effect of the adipose tissue or occur systemically through humoral mediators and metabolic adjustments that change heart hemodynamics and geometry, as well as possibly lung function. ${ }^{(1-3)}$

A recent epidemiological study ${ }^{(4)}$ found a relationship between lung function and left ventricular mass (LVM), although the relationship differed between genders. Functional effects of obesity that are associated with being male or female are common in pulmonary function testing, since fat concentrated in the chest (android obesity) could lead to deeper changes in lung function than could fat concentrated in the hips (gynecoid obesity). In contrast, another study, which had a case-control design and involved children with and without metabolic syndrome, found no relationship between lung function and LVM. ${ }^{(5)}$

Recent evidence suggests that inflammatory mediators act independently of confounding variables on cardiac remodeling in obese individuals, ${ }^{(2,6)}$ as well as on lung function, ${ }^{(7,8)}$ primarily at the level of the small airways. In contrast, there is evidence of purely mechanical cardiopulmonary effects, with no effect of inflammatory mediators, ${ }^{(9,10)}$ or an interaction of mechanical and inflammatory factors in cases of lung function and asthma associated with obesity. ${ }^{(11)}$

Therefore, the primary objective of this exploratory study was to look for correlations between lung function and cardiac dimension variables, in order to test the hypothesis that regardless of being a purely mechanical or gender-related factor, the relative size of the small airways (dysanapsis), as measured indirectly by the ratio of $\mathrm{FEF}_{25-75 \%}$ to FVC $\left(\mathrm{FEF}_{25-75} / \mathrm{FVC}, \%\right)$, is correlated with left ventricular hypertrophy (remodeling), since the small airways are especially susceptible to mechanical-inflammatory interactions and bronchial hyperreactivity. Similarly, we aimed to determine the degree of association between lung function and ventricular mass in the study population, with the goal of guiding future studies related to common mechanisms of cardiac and pulmonary impairment in morbid obesity. To the best of our knowledge, based on our review of currently available databases (Bireme, SciELO, PubMed, Cochrane Library, and Google Academic), this is the first study to investigate this relationship in morbidly obese individuals.

Correspondence to:

Paulo de Tarso Müller. Avenida Senador Filinto Müller, S/N, Vila Ipiranga, Campus da Universidade Federal de Mato Grosso do Sul, Faculdade de Medicina, CEP 79070-

900, Campo Grande, MS, Brasil.

Tel.: 5567 3345-3149. E-mail: paulo.muller@ufms.br

Financial support: None. 


\section{METHODS}

We planned this study based on secondary data obtained from a bariatric surgery outpatient clinic, which is a state referral center for this type of surgery. In this retrospective study, we reviewed the medical records of all obese individuals who were candidates for bariatric surgery between January of 2006 and December of 2010, with the total number of individuals being 192. Individuals underwent a standardized clinical assessment, which was based on an instrument designated "clinical assessment form for obese patients" (a protocol at the department of bariatric surgery), in which detailed information was obtained on anthropometric parameters, degree of obesity, comorbidities, and pressure levels, among other clinical data and relevant tests, assessed by physicians, nutritionists, and nurses working in that department.

The aim of the medical record review was to systematically collect the following clinical data on and test results for morbidly obese individuals (BMI $\geq 40 \mathrm{~kg} /$ $\left.\mathrm{m}^{2}\right)^{(12)}$ : (i) anthropometry; (ii) simple spirometry; (iii) M-mode echocardiography; (iv) reporting of bronchial asthma (diagnosis and/or treatment); (v) reporting of current or former smoking; and (vi) reporting (diagnosis and/or treatment) of systemic arterial hypertension (SAH). Asthma was defined as reporting of a current or prior medical diagnosis. Current or former smoking refers to a longer than 1-year history of smoking, regardless of the number of pack-years. SAH was defined as a current drug treatment for SAH or at least two arterial blood pressure measurements $\geq 140 / 90$ $\mathrm{mmHg}$. Data on the forms, as well as test results, were only accepted if they had been properly recorded within 1 year before surgery. Only 45 patients met all of the above inclusion criteria, of whom 3 were excluded because of an echocardiographic report of acoustic window impairment caused by obesity and 3 were excluded because they did not meet the spirometry quality criteria. The main reasons for exclusion of the remaining cases were not being diagnosed with morbid obesity (136 individuals) and being a morbidly obese patient with no spirometric data (4 individuals), no echocardiographic data (5 individuals), or neither (2 individuals).

Anthropometric data were obtained by using a stadiometer and a scale for obese individuals, and BMI was calculated by the formula weight/height ${ }^{2}$ (in $\mathrm{kg} /$ $\mathrm{m}^{2}$ ). Waist circumference values were not collected, since such values were lacking in many cases. The study was approved by the Human Research Ethics Committee of the Federal University of Mato Grosso do Sul and was in compliance with the Declaration of Helsinki.

Spirometry with forced expiratory maneuver was performed in the pulmonary function section of the department of pulmonology of the university. All tests met the acceptability criteria established in the Brazilian guidelines for pulmonary function testing, ${ }^{(13)}$ and values were corrected to body temperature, pressure saturated. All tests were performed with a Vitatrace VT 130 spirometer (Pró Médico Ltda., Rio de Janeiro, Brazil), with individuals in a sitting position and wearing a nose clip. The equipment was always calibrated in the morning, in accordance with the manufacturer instructions, and the tests were always conducted by one of two trained spirometry technicians belonging to the department of pulmonology. At least three acceptable maneuvers were always performed, and instantaneous flow was expressed as that obtained from the one maneuver with the highest sum of FVC (in $L$ ) and $\mathrm{FEV}_{1}$ (in $\mathrm{L} / \mathrm{min}$ ). The reference values used were those of Pereira et al., ${ }^{(14)}$ and the mean \pm SD of the study population was recorded.

Echocardiography was performed by two cardiologists, who used a Nemio 17-2005 echocardiograph (Toshiba, Tokyo, Japan). Those two cardiologists, one of whom is one of the present authors, work specifically in the echocardiography section of the hospital. For the purposes of this study, only data acquired in M-mode were collected; left ventricle end-diastolic volume (LVDV) and LV end-systolic volume (LVSV) were indirectly measured using the Teicholz formula, and LVM was calculated using the formula by Devereux et al. ${ }^{(15)}$ The measurements were obtained from parasternal LV cross-sections at the level of the papillary muscles. Left atrial (LA) dimensions, LV end-diastolic diameter (LVDD), and LV end-systolic diameter (LVSD) were also measured. We used as criteria for LVM indexation both height to the power of $1.7\left(\mathrm{LVM} / \mathrm{m}^{1.7}\right)$, which is a criterion recommended for obese individuals, and height squared $\left(\mathrm{LVM} / \mathrm{m}^{2}\right)$. Relative LV posterior wall thickness (RLVPWT) was obtained by dividing LV posterior wall thickness (LVPWT) by LVDD.

The results are expressed as mean \pm SD or frequency. Our sample size calculation (PASS software, version 11; NCSS LLC, Kaysville, UT, USA) showed that 40 individuals would be enough to provide a power of $80 \%$ for a significant correlation coefficient of 0.40 at $\alpha=0.05\left(\mathrm{FEF}_{25-75} / \mathrm{FVC}\right.$, \% vs. LVM/LVPWT/RLVPWT). For multiple linear regression analysis (based on LVM), 40 individuals would be necessary to provide a power of $98 \%$ and an $r^{2}=0.37$, in a model with four independent variables (weight, $\mathrm{FEV}_{1}, \mathrm{FVC}$, and $\mathrm{FEF}_{25-75} / \mathrm{FVC}$, \%). The categorical variables reporting of smoking, reporting of asthma, and reporting of SAH were also computed, and gender and reporting of SAH were coded as a binary variable for purposes of statistical adjustment. Correlations between various spirometric and echocardiographic variables were assessed by Pearson's correlation test. Only LVM and LVPWT required log transformation to fit a normal distribution. The relationship between reporting of asthma (diagnosis and/or treatment) or current/former smoking and $\mathrm{FEF}_{25-75} / \mathrm{FVC}$, \%, below or above the lower limit of the normal range, was assessed by Fischer's exact test. The relationship between $\mathrm{FEF}_{25-75} / \mathrm{FVC}$, \% and LVPWT/RLVPWT was tested by partial correlation analysis, adjusted for weight, gender, and $\mathrm{SAH}$, which 
are traditionally the most important determinants of LV hypertrophy in obesity. In order to determine which variable would be the best predictor of LVM (dependent variable), we tested a stepwise multivariate linear regression model, in which the independent variables were only the variables showing a significant correlation ( $p<0.05$ ) with LVM, whether indexed or not. For all calculations and graphs, we used the IBM SPSS Statistics software package, version 20.0 (IBM Corp., Armonk, NY, USA). Results were considered significant at the level of $p \leq 0.05$.

\section{RESULTS}

Of the 45 patients for whom all data were originally available for inclusion, 6 were excluded because of reported failures in M-mode echocardiography or in pulmonary function testing, which did not meet quality criteria. The anthropometric and demographic data of the 39 patients included in the study are shown in Table 1. Females predominated in the study (74.3\%), the mean age of the participants was $35.5 \pm 7.7$ years, and 8 participants were considered super-obese (BMI $>55 \mathrm{~kg} / \mathrm{m}^{2}$ ). Asthma and ever smoking were reported by 7 and 6 individuals, respectively. SAH (diagnosis and/or treatment) was reported to be present in 21 individuals (54\%). Only 1 individual reported both asthma and smoking. The main spirometric and echocardiographic parameters are shown in Table 2. The mean spirometric values were above $80 \%$ of predicted. The mean values of LA diameter, LVM, and $\mathrm{LVM} / \mathrm{m}^{2}$ were increased relative to normal mean values for the Brazilian population. ${ }^{(16)}$

The various correlations between the echocardiographic and spirometric variables are shown in Table 3. No correlation was found between BMI and any of the spirometric variables studied. Chief among the significant correlations is the weak direct relationship between BMI and the variables $\operatorname{LVDD}(r=0.359 ; p<$ $0.05), \operatorname{LVSD}(r=0.387 ; p<0.05), \operatorname{LVDV}(r=0.387 ; p$ $<0.05)$, and LVSV $(r=0.425 ; p<0.01)$. A moderate inverse correlation was found between $\mathrm{FEF}_{25-75} / \mathrm{FVC}$, $\%$ and the variables of LV remodeling (Table 3 ) in the univariate analysis, and this correlation remained statistically significant for LVPWT $(r=-0.355$; $p<$ $0.05)$ and RLVPWT ( $r=-0.349 ; p<0.05)$ even after adjustment for weight, gender, and SAH (Figures $1 \mathrm{~A}$ and $1 \mathrm{~B}$, respectively). The correlation between indexed LVM (in $\mathrm{g} / \mathrm{m}^{1.7}$ ) and $\mathrm{FEF}_{25-75} / \mathrm{FVC}$, \% was borderline for statistical significance ( $p=0.05$; Figure $1 \mathrm{C}$ ). Interestingly, $\mathrm{FEF}_{25-75} / \mathrm{FVC}$, \% did not correlate with the variables of LV internal diameter or LV volume. No correlation was found between $\mathrm{FEF}_{25-75 \%}$ and any of the echocardiographic variables. Fischer's exact test showed no statistically significant association between $\mathrm{FEF}_{25-75} / \mathrm{FVC} \%$, below or above the lower limit of the normal range, and reporting of asthma or smoking ( $p$ $>0.05$ for both).

Stepwise multiple linear regression analysis (Table 4) showed that the variation in LVM among morbidly obese individuals is better predicted by FVC (in L), which explained $36.9 \%$ ( $p<0.0001$ ) of the variation in LVM in the study population. The best predictor of LVM indexed to height squared and LVM indexed to height to the power of 1.7 was $\mathrm{FEV}_{1}$ (in L/min; $\mathrm{p}<$ 0.05 for both; Table 4).

\section{DISCUSSION}

This retrospective study shows there is an independent association between the relative size of the small airways $\left(\mathrm{FEF}_{25-75} / \mathrm{FVC}, \%\right)$ and echocardiographic parameters of ventricular hypertrophy in morbidly obese individuals.

Table 1. Characteristics of the individuals included in the study $(\mathrm{N}=39)$. $^{\mathrm{a}}$

\begin{tabular}{lc}
\hline \multicolumn{1}{c}{ Characteristic } & Result \\
Age, years & $35.5 \pm 7.7$ \\
Height, $\mathrm{cm}$ & $163.1 \pm 9.1$ \\
Weight, $\mathrm{kg}$ & $131.4 \pm 25.9$ \\
$\mathrm{BMI}, \mathrm{kg} / \mathrm{m}^{2}$ & $49.2 \pm 7.6$ \\
$\mathrm{BS}, \mathrm{m}^{2}$ & $2.3 \pm 0.3$ \\
Gender $(\mathrm{M} / \mathrm{F}), \mathrm{n} / \mathrm{n}$ & $10 / 29$ \\
Asthma $(\mathrm{Y} / \mathrm{N}), \mathrm{n} / \mathrm{n}$ & $7 / 32$ \\
Smoking $(\mathrm{Y} / \mathrm{N}), \mathrm{n} / \mathrm{n}$ & $6 / 33$ \\
SAH $(\mathrm{Y} / \mathrm{N}), \mathrm{n} / \mathrm{n}$ & $21 / 18$ \\
\hline
\end{tabular}

BS: body surface; M: male; F: female; Y: yes; N: no; and SAH: systemic arterial hypertension. aValues expressed as mean $\pm S D$, except where otherwise indicated.

Table 2. Spirometric and echocardiographic parameters $(\mathrm{N}=39)$.

\begin{tabular}{lc}
\multicolumn{1}{c}{ Parameter } & Result \\
Spirometry & \\
FEV $_{1}, \mathrm{~L}$ & $2.8 \pm 0.6$ \\
FEV $_{1}, \%$ predicted & $87.9 \pm 11.8$ \\
FVC, L & $3.4 \pm 0.8$ \\
FVC, \% predicted & $88.4 \pm 11.7$ \\
FEV $_{1} /$ FVC, \% & $83.1 \pm 6.4$ \\
FEF $_{25-75} / \mathrm{FVC}, \%$ & $99.5 \pm 30.2$ \\
Echocardiography & \\
LA, mm & $36.2 \pm 4.1$ \\
ST, mm & $11.6 \pm 4.4$ \\
LVPWT, mm & $10.7 \pm 2.3$ \\
RLVPWT & $0.2 \pm 0.1$ \\
LVDD, mm & $48.2 \pm 4.1$ \\
LVSD, mm & $29.6 \pm 3.7$ \\
LVDV, mL & $108.9 \pm 21.7$ \\
LVSV, mL & $34.9 \pm 11.2$ \\
LVM, g & $248.3 \pm 84.9$ \\
LVM, g/m & $106.7 \pm 30.4$ \\
LVM, g/m & $92.1 \pm 26.1$ \\
\hline LA &
\end{tabular}

LA: left atrium; ST: septal thickness; LVPWT: left ventricular posterior wall thickness; RLVPWT: relative left ventricular posterior wall thickness; LVDD: left ventricular end-diastolic diameter; LVSD: left ventricular end-systolic diameter; LVDV: left ventricular end-diastolic volume; LVSV: left ventricular end-systolic volume; and LVM: left ventricular mass. 
Table 3. Univariate correlations of anthropometric and spirometric variables with transthoracic echocardiography variables (M-mode) in the sample as a whole $(\mathrm{N}=39)$.

\begin{tabular}{|c|c|c|c|c|c|c|c|c|c|c|c|}
\hline \multirow[t]{2}{*}{ Parameter } & \multicolumn{6}{|c|}{ LV hypertrophy } & \multicolumn{5}{|c|}{ LV diameter/volume } \\
\hline & $\begin{array}{c}\text { LVM, } \\
\text { g }\end{array}$ & $\begin{array}{l}\text { LVM, } \\
\mathrm{g} / \mathrm{m}^{2}\end{array}$ & $\begin{array}{l}\text { LVM, } \\
\mathbf{g} / \mathbf{m}^{1.7}\end{array}$ & $\begin{array}{l}\text { ST, } \\
\text { mm }\end{array}$ & $\begin{array}{c}\text { LVPWT, } \\
\text { mm }\end{array}$ & RLVPWT & $\begin{array}{l}\text { LA, } \\
\mathrm{mm}\end{array}$ & $\begin{array}{c}\text { LVEDD, } \\
\mathrm{mm}\end{array}$ & $\begin{array}{c}\text { LVESD, } \\
\mathrm{mm}\end{array}$ & $\begin{array}{c}\text { LVEDV, } \\
\text { mL }\end{array}$ & $\begin{array}{c}\text { LVESV, } \\
\text { mL }\end{array}$ \\
\hline \multicolumn{12}{|l|}{ Anthropometry } \\
\hline $\mathrm{BMI}, \mathrm{kg} / \mathrm{m}^{2}$ & 0.175 & 0.192 & 0.227 & 0.078 & 0.092 & -0.046 & 0.069 & $0.359^{*}$ & $0.387^{*}$ & $0.387^{*}$ & $0.425^{\ddagger}$ \\
\hline Weight, kg & $0.476^{\dagger}$ & 0.293 & 0.312 & 0.160 & $0.360^{*}$ & 0.169 & $0.380^{*}$ & $0.447^{\dagger}$ & $0.476^{\dagger}$ & $0.455^{\ddagger}$ & $0.556^{\ddagger}$ \\
\hline \multicolumn{12}{|l|}{ Spirometry } \\
\hline $\mathrm{FEV}_{1}, \mathrm{~L}$ & $0.590^{\ddagger}$ & $0.388^{*}$ & $0.401^{*}$ & 0.162 & $0.389^{*}$ & 0.212 & $0.473^{\dagger}$ & $0.406^{\dagger}$ & $0.388^{*}$ & $0.386^{*}$ & $0.488^{\ddagger}$ \\
\hline $\mathrm{FEV}_{1}, \%$ predicted & 0.147 & 0.232 & 0.154 & 0.110 & -0.029 & -0.102 & 0.015 & 0.217 & 0.196 & 0.238 & 0.162 \\
\hline FVC, L & $0.584^{\dagger}$ & $0.346^{*}$ & $0.380^{*}$ & 0.164 & $0.429^{\ddagger}$ & 0.264 & $0.513^{\ddagger}$ & $0.365^{*}$ & 0.315 & $0.366^{*}$ & $0.418^{\dagger}$ \\
\hline FVC, \% predicted & 0.087 & 0.159 & 0.256 & 0.071 & -0.017 & -0.061 & 0.019 & 0.133 & 0.048 & 0.194 & 0.038 \\
\hline $\mathrm{FEV}_{1} / \mathrm{FVC}, \%$ & 0.003 & 0.077 & 0.040 & -0.002 & -0.114 & -0.145 & -0.082 & 0.118 & 0.197 & 0.047 & 0.167 \\
\hline $\mathrm{FEF}_{25-75} / \mathrm{FVC}, \%$ & $-0.397^{*}$ & -0.275 & $-0.318 \dagger$ & -0.054 & $-0.453^{\ddagger}$ & $-0.404^{\ddagger}$ & -0.168 & 0.009 & 0.041 & -0.057 & -0.020 \\
\hline
\end{tabular}

LV: left ventricular; LVM: LV mass; ST: septal thickness; LVPWT: LV posterior wall thickness; RLVPWT: relative LV posterior wall thickness; LA: left atrium; LVDD: LV end-diastolic diameter; LVSD: LV end-systolic diameter; LVDV: LV end-diastolic volume; and LVSV: LV end-systolic volume. ${ }^{*} p<0.05 ;{ }^{\dagger} p=0.05 ;{ }^{\ddagger} p<0.01$
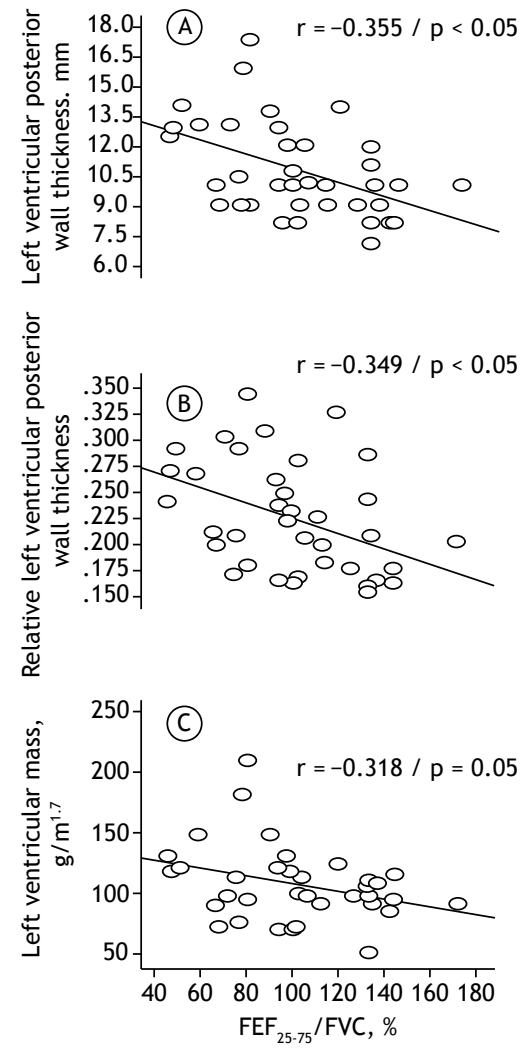

Figure 1. Correlation of $\mathrm{FEF}_{25-75} / \mathrm{FVC}$, \%, adjusted for the variables weight, gender, and systemic arterial hypertension, with left ventricular posterior wall thickness, in $A$; with relative left ventricular posterior wall thickness, in $B$; and with left ventricular mass adjusted for body size in obese individuals, in C.

In addition, $\mathrm{FVC}$ (in $\mathrm{L}$ ) and $\mathrm{FEV}_{1}$ (in $\mathrm{L} / \mathrm{min}$ ) were found to be important predictors of LVM in grams or indexed to body surface area.

Both LVM and LV internal diameters are increased in obesity, regardless of SAH. ${ }^{(17)}$ In our study, we found no relationship of BMI with LVM in grams or indexed to body surface area or with LVPWT, but we found a relationship of BMI with LV internal diameters and LV volumes, which is consistent with the literature. $(2,17)$ This positive association is likely to be due to increased preload and increased cardiac output, causing ventricular dilatation, which could later progress to LV remodeling. ${ }^{(18)}$

The literature shows inconsistent associations between BMI and spirometric results, with some studies showing an association ${ }^{(19)}$ and others not showing any. ${ }^{(20)}$ This is probably due to differences in gender ratio among studies, since the android type of obesity favors the correlation between BMI and lung function, unlike the gynecoid phenotype, which does not produce excessive accumulation of fat mass in the chest. In our study, females predominated (74\%), which partly explains the lack of correlation between any spirometric variable and BMI.

The relationships of FVC, $\mathrm{FEV}_{1}$, and $\mathrm{FEF}_{25-75 \%}$ with LVM and LVPWT have been studied in (non-obese) elderly individuals with cardiovascular disease, and the results differ among studies in regard to the direction of the correlation, with correlations being positive ${ }^{(21)}$ or negative, ${ }^{(22)}$ which more strongly reflects loss of lung function associated with advanced age and with the effects of SAH and pulmonary hypertension, as well as with the pulmonary restrictive effects of cardiomegaly. One study ${ }^{(4)}$ showed an inverse relationship between LVM and FVC in nonsmoking females and a direct relationship between LVM and FVC in nonsmoking males under 60 years of age. The fact that most of our sample consists of females (74\%) suggests that, in morbidly obese individuals, the direction of the correlation may be different for some lung function variables.

$\mathrm{FEF}_{25-75} / \mathrm{FVC}, \%$ is a measure that corrects to some extent for the large variability found in $\mathrm{FEF}_{25-75 \%}$ alone and reflects changes predominantly in the small airways, being adjusted for lung size on the basis of FVC. ${ }^{(17)}$ The correlations of $\mathrm{FEF}_{25-75} / \mathrm{FVC}$, \% with LVM indexed 
Table 4. Stepwise multiple linear regression for the dependent variable left ventricular mass (in grams or indexed to body surface area; $\mathrm{N}=39$ ).

\begin{tabular}{cccccc} 
Dependent variable & Predictor variable & Beta & $95 \%$ Cl & Adjusted $\mathbf{R}^{2}$ & $\mathbf{p}$ \\
LVM, g & $\mathrm{FVC}, \mathrm{L}$ & 0.60 & $0.43-1.13$ & 0.369 & $<0.001$ \\
$\mathrm{LVM}, \mathrm{g} / \mathrm{m}^{2}$ & $\mathrm{FEV}_{1}, \mathrm{~L} / \mathrm{min}$ & 0.38 & $0.29-2.8$ & 0.126 & $<0.05$ \\
$\mathrm{LVM}, \mathrm{g} / \mathrm{m}^{1.7}$ & $\mathrm{FEV}_{1}, \mathrm{~L} / \mathrm{min}$ & 0.40 & $0.2-1.3$ & 0.161 & $<0.05$ \\
\hline
\end{tabular}

LVM: left ventricular mass.

to body surface area (in $\mathrm{g} / \mathrm{m}^{1.7}$ ) and with LVPWT/ RLVPWT, correlations that remained after adjustment for weight, gender, and SAH, possibly reflect the direct mechanical effects of obesity, but may also suggest that there are other independent (inflammatory or lipotoxic) mechanisms.

Since research on the subject is scarce, there is limited evidence that the small airways are independently affected by obesity, as has been reported in nonsmoking males. ${ }^{(23)}$ The hypotheses raised in that study ${ }^{(23)}$ include an increase in blood volume in obese individuals, causing bronchial vessel congestion; the presence of increased levels of very-low-molecular-weight lipoproteins, which could trigger the release of histamine; and altered lipoprotein metabolism in obesity, which could elicit and amplify these effects.

Recent data in the literature also indicate that obesity is characterized by hyperresponsiveness to methacholine, predominantly in the small airways, ${ }^{(24)}$ and that this hyperresponsiveness correlates better with $\mathrm{FEF}_{25-75} /$ FVC, \%. ${ }^{(25)}$ On this point, a recent study suggests that groups of obese individuals with hyperresponsiveness are associated with greater LVM. ${ }^{(26)}$ Small airway hyperresponsiveness in obese individuals also could be partially explained by dysanapsis (which is assessed indirectly by $\mathrm{FEF}_{25-75} / \mathrm{FVC}$, \%), a term coined by Green et al. (27) to explain the large interindividual variability in airway size, regardless of lung parenchyma size. An important predictor of LVM, BMI correlated directly with cardiac size and mass in several studies, although lean body mass remains a better predictor of LVM. $(2,28,29)$ This retrospective study found no correlations between BMI and LVM (in grams or indexed to body surface area), which is in agreement with another study, ${ }^{(30)}$ and this is possibly due to differences in obesity phenotypes, prevalence of SAH, and number of individuals studied.
Of note in our study is the fact that FVC (in L) was the best predictor of variation in LVM (in g), explaining $37 \%$ of this variation in the study population, which suggests that reduced lung volume may be an important variable in establishing a predictive model for LVM in obese individuals in future studies. In turn, LVM correlates with cardiovascular morbidity and mortality.

Among the limitations of our study is the fact that our sample was small, consisting of candidates for bariatric surgery, was limited by the criterion of including only morbidly obese and super-obese individuals, and was based on criteria that were unclear in the medical charts, such as the diagnosis of asthma or SAH. In addition, data on diabetes were not collected, although the relationship between diabetes and LVM is inconsistent in the literature. Other important limitations were the limited acoustic window in the analysis of M-mode echocardiographic variables in obese individuals and the lack of a specific, standardized protocol for M-mode echocardiography, since we did not obtain data on inter-rater agreement for the two echocardiographers. In this regard, because this was a retrospective study, we sought not to use echocardiographic data for which accuracy is significantly decreased by the effects of obesity on the acoustic window, such as ejection fraction and Doppler echocardiography data.

We therefore conclude that the small airways in morbidly obese individuals have a correlation with cardiac hypertrophy, regardless of usual anthropometric variables, gender, or SAH. This study reveals that factors other than mechanical and/or hemodynamic limitations imposed by increased body mass may be important in the joint changes seen in the small airways and in cardiac hypertrophy. In addition, further studies are needed to examine the impact that lung function parameters have on predictive equations for LVM in obese individuals.

\section{REFERENCES}

1. Poirier P, Giles TD, Bray GA, Hong Y, Stern JS, Pi-Sunyer FX, et al. Obesity and cardiovascular disease: pathophysiology, evaluation, and effect of weight loss. Arterioscler Thromb Vasc Biol. 2006;26(5):96876. http://dx.doi.org/10.1161/01.ATV.0000216787.85457.f3

2. Ashrafian $H$, Athanasiou $T$, le Roux CW. Heart remodelling and obesity: the complexities and variation of cardiac geometry. Heart .2011;97(3):171-2. http://dx.doi.org/10.1136/hrt.2010.207092

3. Salome CM, King GG, Berend N. Physiology of obesity and effects on lung function. J Appl Physiol (1985). 2010;108(1): 206-11. http:// dx.doi.org/10.1152/japplphysiol.00694.2009

4. Charles LE, Burchfiel CM, Andrew ME, Gu JK, Petrini MF, Butler KR Jr. Pulmonary function and left ventricular mass in African Americans: the Atherosclerosis Risk in Communities (ARIC) study.
Echocardiography. 2012;29(2):131-9. http://dx.doi.org/10.1111/ j.1540-8175.2011.01550.x

5. Del Río-Camacho G, Domínguez-Garrido MN, Pita J, Aragón I, Collado R, Soriano-Guillén L. Left ventricular mass, forced baseline spirometry and adipocytokine profiles in obese children with and without metabolic syndrome [Article in Spanish]. An Pediatr (Barc). 2013;78(1):27-34. http://dx.doi.org/10.1016/j.anpedi.2012.05.010

6. Lai YH, Liu CC, Kuo JY, Hung TC, Wu YJ, Yeh HI, et al. Independent effects of body fat and inflammatory markers on ventricular geometry, midwall function, and atrial remodeling. Clin Cardiol. 2014;37(3):172-7. http://dx.doi.org/10.1002/clc.22242

7. Hickson DA, Burchfiel CM, Petrini MF, Liu J, Campbell-Jenkins BW Bhagat $R$, et al. Leptin is inversely associated with lung function 
in African Americans, independent of adiposity: the Jackson Heart Study. Obesity (Silver Spring). 2011;19(5):1054-61. http://dx.doi. org/10.1038/oby.2010.240

8. Lecube A, Sampol G, Mu-oz X, Ferrer R, Hernández C, Simó R. TNF- $\alpha$ system and lung function impairment in obesity. Cytokine. 2011;54(2):121-4. http://dx.doi.org/10.1016/j.cyto.2011.01.010

9. Held M, Mittnacht M, Kolb M, Karl S, Jany B. Pulmonary and cardiac function in asymptomatic obese subjects and changes following a structured weight reduction program: a prospective observational study. PLoS One. 2014;9(9):e107480. http://dx.doi.org/10.1371/ journal.pone. 0107480

10. Hickson DA, Liu J, Bidulescu A, Burchfiel CM, Taylor HA, Petrini MF. Pericardial fat is associated with impaired lung function and a restrictive lung pattern in adults: the Jackson Heart Study. Chest. 2011;140(6):1567-73. http://dx.doi.org/10.1378/chest.11-0258

11. Santamaria F, Montella S, Pietrobelli A. Obesity and pulmonary disease: unanswered questions. Obes Rev. 2012;13(9):822-33. http://dx.doi.org/10.1111/j.1467-789X.2012.01008.x

12. World Health Organization. Obesity: preventing and managing the global epidemic. Report of a WHO consultation. Geneva: WHO 1998

13. Sociedade Brasileira de Pneumologia e Tisiologia. Diretrizes para testes de função pulmonar. J Pneumol. 2002; 28(Suppl 3):S1-S238.

14. Pereira CA, Sato T, Rodrigues SC. New reference values for forced spirometry in white adults in Brazil. J Bras Pneumol. 2007;33(4):397406. http://dx.doi.org/10.1590/S1806-37132007000400008

15. Devereux RB, Alonso DR, Lutas EM, Gottlieb GJ, Campo E, Sachs I, et al. Echocardiographic assessment of left ventricular hypertrophy: comparison to necropsy findings. Am J Cardiol. 1986;57(6):450-8. http://dx.doi.org/10.1016/0002-9149(86)90771-X

16. Angelo $L C$, Vieira $M L$, Rodrigues $S L$, Morelato $R L$, Pereira $A C$, Mill JG, et al. Echocardiographic reference values in a sample of asymptomatic adult Brazilian population. Arq Bras Cardiol. 2007;89(3):168-73, 184-90

17. Lauer MS, Anderson KM, Levy D. Separate and joint influences of obesity and mild hypertension on left ventricular mass and geometry: the Framingham Heart Study. J Am Coll Cardiol. 1992;19(1):130-4 http://dx.doi.org/10.1016/0735-1097(92)90063-S

18. Rider OJ, Petersen SE, Francis JM, Ali MK, Hudsmith LE, Robinson $M R$, et al. Ventricular hypertrophy and cavity dilatation in relation to body mass index in women with uncomplicated obesity. Heart. 2011;97(3):203-8. http://dx.doi.org/10.1136/hrt.2009.185009

19. Wei YF, Wu HD, Chang CY, Huang CK, Tai CM, Hung CM, et al. The impact of various anthropometric measurements of obesity on pulmonary function in candidates for surgery. Obes Surg.
2010;20(5):589-94. http://dx.doi.org/10.1007/s11695-009-9961-0

20. Gabrielsen AM, Lund MB, Kongerud J, Viken KE, Røislien J, Hjelmesæth J. The relationship between anthropometric measures, blood gases, and lung function in morbidly obese white subjects. Obes Surg. 2011;21(4):485-91. http://dx.doi.org/10.1007/s11695010-0306-9

21. Ricart S, Casan P, Bellido-Casado J, González M, Cotes C, López L, et al. Lung function in cardiac dysfunction [Article in Spanish]. Arch Bronconeumol. 2004;40(2):62-6. http://dx.doi.org/10.1016/S03002896(04)75474-5

22. Enright $\mathrm{PL}$, Kronmal RA, Smith VE, Gardin JM, Schenker MB, Manolio TA. Reduced vital capacity in elderly persons with hypertension, coronary heart disease, or left ventricular hypertrophy. The Cardiovascular Health Study. Chest. 1995;107(1):28-35. http:// dx.doi.org/10.1378/chest.107.1.28

23. Rubinstein I, Zamel N, DuBarry L, Hoffstein V. Airflow limitation in morbidly obese, nonsmoking men. Ann Intern Med. 1990;112(11):828-32. http://dx.doi.org/10.7326/0003-4819-112-11 828

24. Skloot G, Schechter C, Desai A, Togias A. Impaired response to deep inspiration in obesity. J Appl Physiol (1985). 2011;111(3):726-34 http://dx.doi.org/10.1152/japplphysiol.01155.2010

25. Zerah-Lancner F, Boyer L, Rezaiguia-Delclaux S, D'Ortho MP, Drouot $X$, Guilloteau-Schoennagel I, et al. Airway responsiveness measured by forced oscillation technique in severely obese patients, before and after bariatric surgery. J Asthma. 2011;48(8):818-23. http://dx.doi.org/ 10.3109/02770903.2011.613508

26. Gagnon-Audet AA, Poirier P, Turcotte H, Martin J, Bastien M, Simard $S$, et al. Influence of cardiac dysfunction and systemic inflammation on pulmonary function and airway responsiveness in obese subjects. Clin Invest Med. 2013;36(5):E255-63.

27. Green M, Mead J, Turner JM. Variability of maximum expiratory flowvolume curves. J Appl Physiol. 1974;37(1):67-74

28. Rocha IE, Victor EG, Braga MC, Barbosa e Silva O, Becker Mde M. Echocardiography evaluation for asymptomatic patients with severe obesity. Arq Bras Cardiol. 2007;88(1):52-8. http://dx.doi.org/10.1590/ S0066-782X2007000100009

29. Ballo P, Motto A, Mondillo S, Faraguti SA. Impact of obesity on left ventricular mass and function in subjects with chronic volume overload. Obesity (Silver Spring). 2007;15(8):2019-26. http://dx.doi. org/10.1038/oby.2007.241

30. Ribeiro Filho FS, Rosa EC, Faria AN, Lerário DD, Ferreira SR, Kohlmann O, et al. Obesidade, hipertensão arterial e suas influências sobre a massa e função do ventrículo esquerdo. Arq Bras Endocrinol Metab. 2000;44(1):6471. http://dx.doi.org/10.1590/S0004-27302000000100011 